\title{
Anomalies of Section 2 of the Homicide Act 1957
}

\author{
A Kenny Balliol College, Oxford
}

\section{Author's abstract}

\begin{abstract}
Section 2 of the 1957 Homicide Act is indefensible: the concept of 'mental responsibility' is a hybrid which turns the psychiatrist witness either into a thirteenth juryman or a spare barrister. But reform does not lie along the lines suggested by the Butler Committee or the Criminal Law Revision Committee. The latter leaves the jury with insufficient guidance; the former returns to the bad eighteenth century policy of treating mental illness not as a factor in determining responsibility but as a status exempting from responsibility. The much criticised McNaughton rules provide a sounder basis for deciding where responsibility should be assigned in criminal cases.
\end{abstract}

I regard Section 2 of the Homicide Act 1957 as quite indefensible. Indeed, I am glad to see that Professor Griew and I are in almost exact agreement about what, from a conceptual point of view, is the matter with the Section. To illustrate this let me quote from my Blackstone lecture of 1982 (1).

'The term "mental responsibility" is a curious one. Whether someone is to be held responsible for his acts seems to be either a legal question - is a man acting in such and such a way in such and such a mental condition guilty of a legal offence - or a moral question - should people who act thus in such and such mental conditions be convicted and sentenced by the laws. The word "mental" seems to belong with "capacity" or "disorder" or "disease" rather than with "responsibility". In practice "mental responsibility" has come to mean something very close to "a mental state such that psychiatrists believe he ought to be convicted". Because the word "mental" precedes "responsibility" the matter seems to be one proper for the expert evidence of the experts on mental health and disease: namely the psychiatrists. Because the matter at issue is responsibility, ie whether the accused is to be regarded as suitable for conviction and punishment, the expert is being asked to testify, in a case where there is no dispute about the acts and omissions of the

\section{Key words}

Section 2 of the Homicide Act; McNaughton Rules; mentally abnormal offenders; diminished responsibility. accused, whether in his opinion the accused should be convicted .... The question whether an individual should be convicted should be a question, not for the psychiatrists, but for the jury; the question whether persons of a certain kind should be punished is a question not for the psychiatrist but for the legislature. But a psychiatrist who is asked to give expert evidence when a defence of diminished responsibility is led can hardly avoid giving his opinion on these two matters.'

The position in which a psychiatrist is placed by the requirements of this Section and the questioning of judge and counsel can be very painful. The position can be equally painful whether it turns into that of extra barrister or of thirteenth juryman. This afternoon we learnt how unfair the present statute is to mentally abnormal offenders: it will, as Dr Dell shows, depend on their psychiatrists whether, on the same facts, they will be found guilty of murder and serve a life sentence, or have a plea of diminished responsibility accepted and suffer only the lesser penalties of manslaughter. It is clear that the statute is overdue for reform.

However, I do not believe that reform lies along the lines suggested by the Butler Committee or the Criminal Law Revision Committee (CLRC). According to the Butler proposal, there should be no conviction for murder if there is medical or other evidence that (the accused) was suffering from a form of mental disorder as defined in section 4 of the Mental Health Act 1959 and if, in the opinion of the jury, the mental disorder was such as to be an extenuating circumstance which ought to reduce the offence to manslaughter'. The CLRC had some misgivings about the final clause of this proposal and substituted, as a description of the necessary degree of mental disorder 'such as to be a substantial enough reason to reduce the offence to manslaughter'.

It is a welcome element in each of these formulations that it is made clear that the relevant opinion about responsibility is that of the jury, not of the expert witnesses. However, the new proposal surely turns the jury adrift in a difficult area without sufficient guidance as to how they should form their opinion. The statute will give them no help; and all the judge will be able to tell them is that manslaughter is what the 
jury thinks is manslaughter.

It will be open to the jury to draw the line between murder and manslaughter where it is now drawn (so that roughly ninety per cent of those who raise the diminished responsibility defence are successful). But it will also be open to them to draw the line on the verge of insanity, so that of mentally disordered killers less than ten per cent might escape conviction for murder. (If juries showed themselves disposed to behave in that way, of course, the insanity defence itself might recover from its present unpopularity, and there might be more acquittals.)

It is necessary, therefore, to consider the Butler-type proposals for dealing with diminished responsibility together with the Butler committee's proposals about the insanity defence. A Special Verdict, Butler proposed, could be reached in two ways. In the first place, evidence of mental disorder might go to show that the accused lacked the mens rea for the crime with which he was charged. In the second place, evidence of mental disorder should prevent the conviction of someone who performed a prohibited act with the relevant mens rea, if the jury believe that at the time of the act or omission charged the defendant was suffering from severe mental illness or severe subnormality.

To escape conviction it would not be necessary to show that the accused's unlawful act was the product of his mental disorder. The Butler committee regarded this as unnecessary, since it is difficult to be certain how much of a person's behaviour is affected by mental disease or defect.

I have argued more than once that this proposal is misguided. It is rash to proceed from the difficulty of being sure that there is no connection between mental disorder and a particular crime to the very sweeping generalisation that mental disorder has a causal effect on every single action of the affected person. To illustrate the radical nature of the Butler proposal, I put forward the following imaginary case.

Let us suppose that an academic suffers from paranoid delusions that his colleagues are constantly plagiarising his work, and that they are denying him the promotion which is due to his talents (which in his own deluded opinion amount to genius). This will bring him within the Butler Committee's definition of a severely mentally disordered person. Let us suppose that while subject to these delusions he makes careful and efficient plans for the secret poisoning of his mother-in-law, so that he can enjoy the large fortune which he stands to inherit at her death. It does not seem obvious that his mental disorder should excuse him from criminal responsibility for a premeditated murder which has no connection with it, in the sense that the topics of his delusions form no part of his reasons for committing it. No doubt his mental disorder entitles him to sympathy; he would be equally entitled if he were blind or had lost the use of his legs; but that would not exempt him from criminal responsibility.

The most substantial objection to the Butler committee's proposals is that it treats insanity, not as a factor in determining responsibility, but as a status exempting from responsibility. This is a return to the policy of the eighteenth century and earlier, when the mentally disordered were regarded as a category outside the bounds of responsibility in the same way as children or brute beasts. Treating madness as a status rather than a factor has two bad effects. On the one hand, it gives a certified mental patient a licence which is not given to others: he knows that there are certain things which he may do without being held criminally responsible, while all others not of the same status will be held responsible. On the other hand, it attaches a stigma to insanity by assuming, without any need of proof, that insanity as such predisposes to criminal action.

In the law as it stands, the only case in which a certain status exempts from, or diminishes, responsibility is the case of the mother who has just given birth. The Infanticide Act of 1938 provides that if a woman causes the death of her child under 12 months, where the court is satisfied that the balance of her mind has been disturbed by reason of her not having fully recovered from the effect of giving birth, or because of the effect of lactation, she may be punished as for manslaughter rather than for murder. The Butler committee recommends the repeal of this act, for good reasons. But the reasons which the committee gives for rejecting a special status for mentally unbalanced new mothers seem to be equally good reasons for rejecting a special status for any mentally disordered persons simply as such.

If Section 2 is unsatisfactory as it stands, and if the Butler proposals for reforming it and the insanity defence are unsatisfactory, what should replace the defence of diminished responsibility? I believe that it should not be replaced at all, and that the insanity defence should be the only way of avoiding conviction in a case where it is clear that the accused caused death with the relevant mens rea of intention or recklessness. I would agree with many of the previous speakers, and with the Butler committee itself, that the anomalies of the diminished responsibility defence could be removed, while preserving the good effects it allows, if the mandatory life sentence for murder was to be replaced by a much greater discretion in sentencing where there are mitigating circumstances. But unlike other contributors, I would like to see the diminished responsibility defence abolished whether or not the mandatory life sentence remains.

This is because - and here I reveal my antediluvian convictions - I do not think that the McNaughton Rules are at all as bad as they have been made out to be. I was struck by the fact that when Dr Hamilton wished to illustrate the defects of the Rules he quoted two cases, neither of which threw any discredit on the Rules themselves, considered as a criterion for deciding when 
an accused should be relieved of criminal responsibility. The first concerned a patient who on his own diagnosis, was insane according to the McNaughton criteria. In the second case, the anomalies which he pointed out arose not from the Rules, but from much more recent legislation governing the custody of those held under section 65 of the Mental Health Act of 1959.

There are three things to be distinguished when we apply the judicial process to those accused of an offence, and in particular to mentally disordered offenders. The first is the attachment of a stigma to what has been done. The second is the detention of the offender once convicted and sentenced. The third is the place and style of his incarceration while he is detained as sentenced. In my view it is important to unite stigma and detention more than we now do; but to separate detention from conditions of incarceration, and indeed to remove the third from the courts altogether.

In my view there is no injustice in attaching a stigma to mentally disordered offenders, provided they do not come within the McNaughton Rules. Nor is there any injustice in, after conviction, sentencing them to loss of liberty in the same way as normal offenders are sentenced. If the mandatory life sentence were ended, then in appropriate cases the mental disorder could be taken into account when deciding the appropriate length of loss of liberty. Mental illness sufficient to nullify the mens rea necessary for a crime should, as now, totally remove criminal responsibility. The only reason for giving a Special Verdict rather than a complete acquittal is to give the court the standing to enforce loss of liberty on an innocent person who may be highly dangerous if left at large.

But where someone has been sentenced to detention, it is not at all clear why it should be the court which decides whether the detention should be served in prison or in a secure hospital. If a convicted criminal suffers from a physical illness or handicap, it is not the court which convicts him that decides whether he should move to the prison hospital, or what provisions should be made in the penal system for handicapped detainees. Why should it not be the same with mental illness and mental handicap?

The McNaughton Rules, I believe, do provide the basis for a just criterion to discriminate where responsibility should be assigned in criminal cases. I have argued this in my book Freewill and Responsibility (2). I argue there that on a deterrent theory of punishment, the function of the criminal law is to provide an input to the practical reasoning of those who are considering, or tempted to, the commission of a crime. This function, I maintain, is not inapplicable to those who are mentally ill. The following is taken from page 84 of my book.

'The McNaughton Rules recognise that even those with severe mental illnesses conduct a great part of their lives in accordance with practical reasoning in the light of the alternatives open to them and the consequences of those alternatives. To the extent that they can do so, they can be influenced by the penalties that the law holds out for intentional wrongdoing. To the extent that their delusions vitiate their reasoning by disguising from them the nature of what they are doing, or the moral and legal consequences of their actions, they will fall within the exemptions provided by the McNaughton Rules. Beyond this, there is nothing unjust to them in holding them criminally responsible for their actions: and there may well be an injustice to others in removing from them the deterrents which the law holds out to the sane.'

But while I think that the McNaughton Rules are fundamentally sound, I certainly do not claim that they are completely in order as they stand and as they have been interpreted. In particular, the Rule that an accused can escape liability if he is under such a defect of reason, from a disease of the mind, as not to know what he was doing was wrong is, in itself, an excellent one; but it has been nullified by the confused decision in Windle ((1952) 2 All ER1) which is commonly taken to show that 'wrong' means 'against the law'. If that is what it means (which is not clear because the Lord Chief Justice's references to 'the law of God and man' make it unclear what is meant by 'law' here) then Windle should be overruled.

In jurisdictions where the McNaughton Rules are in full force, and there is no defence comparable to Section 2 of the Homicide Act, psychiatrists often make on oath palpably false statements about the accused's ability to form the intentions etc necessary for the mens rea. They do this, no doubt, out of sympathy for their patients and a desire to secure an acquittal for them. Similarly, under Section 2, one suspects that perfectly rational and fully capable persons who have killed people close to them have succeeded in pleas of diminished reponsibility because psychiatrists have been willing to exploit the confusions of the Act's wording in order to prevent a mercy killer from being sentenced to life imprisonment. I don't myself share the sympathy for mercy killing which has been expressed from time to time. But whether or not mercy killers should be treated like other deliberate killers is a matter for Parliament, not the expert witness, to decide. Until Parliament decides otherwise I believe that the present law should be enforced, and that nothing which savours of perjury should be done to circumvent it.

We seem to be all agreed that the present law places psychiatrists in a very false position. It constantly tempts them to quasi-perjure themselves. (I say 'quasiperjure' rather than perjure, because what they are asked to testify to is a piece of confused nonsense; and swearing to a piece of nonsense is not quite the same as swearing to a falsehood). It constantly allows them, similarly, to quasi-legislate, to take into their own hands in the individual case something which it should be for Parliament to decide in general terms. Thirdly, 
it brings the profession into disrepute by providing, from time to time, the spectacle of eminent experts in the field contradicting each other on matters which look to the layman like elementary and fundamental features of their discipline.

In my Blackstone lecture (3) I suggested, as many of us have done here, that the first two evils could be remedied by the abolition of Section 2 of the Homicide Act. As a remedy for the third, I suggested that the provision of expert evidence should be taken as far as possible out of the adversarial context. The experts should be appointed by the court, not by the parties; their evidence should only be admitted if they were in substantial agreement; it should then be presented to the court by one of them, who could be cross-examined by either party.

If Section 2 were abolished, if the McNaughton Rules were brought back to their original amplitude, if the issue of prison vs hospital were taken from the courts and given to those responsible for penal custody, and if the expert evidence were taken out of the adversarial context, we might hope to see a psychiatric jurisprudence which could be rationally defended, and fairly, honestly, and decently implemented. This would be far from the present position.

Anthony Kenny is a philosopher and Master of Balliol के College, Oxford University.

\section{References}

(1) Kenny A. Blackstone lecture. Reprinted in The ivory tower. London: Basil Blackwell, 1985.

(2) Kenny A. Freewill and responsibility. London: Routledge and Kegan Paul, 1978.

(3) See reference (1): 215 